\title{
Cutaneous graft-versus-host disease after hematopoietic stem cell transplant - a review*
}

\author{
Cesar Daniel Villarreal Villarreal ${ }^{1}$ \\ Jose Carlos Jaime Pérez ${ }^{1}$
}

\author{
Julio Cesar Salas Alanis² \\ Jorge Ocampo Candiani ${ }^{1}$
}

DOI: http:/ / dx.doi.org/10.1590/abd1806-4841.20164180

\begin{abstract}
Graft-versus-host disease (GVHD) is a major complication of allogeneic hematopoietic stem cell transplants (allo-HSCT) associated with significant morbidity and mortality. The earliest and most common manifestation is cutaneous graft-versus-host disease. This review focuses on the pathophysiology, clinical features, prevention and treatment of cutaneous graft-versus-host disease. We discuss various insights into the disease's mechanisms and the different treatments for acute and chronic skin graft-versus-host disease.
\end{abstract}

Keywords: Graft vs host disease; Hematopoietic stem cell transplantation; Hematopoietic stem cells

\section{INTRODUCTION}

Graft-versus-host disease (GVHD) is commonly observed after allogeneic hematopoietic stem cell transplants (allo-HSCT), but rarely after transfusions or solid organ transplants. ${ }^{1}$ GVHD is a major cause of morbidity and mortality, affecting $40-60 \%$ of allo-HSCT recipients, and accounting for $15 \%$ of deaths following this procedure. ${ }^{2}$ Clinical manifestations of GVHD after HSCT transplantation include: fever, cutaneous rash, severe gastrointestinal manifestations and impaired liver function.

The earliest and most common manifestation is cutaneous GVHD and some authors have found that it entails a worse prognosis. ${ }^{3}$ Lesions usually start on the pinnae and neck and progress to confluent lesions on the cheeks, upper trunk, palms and soles, which may become generalized. ${ }^{4}$ Patients may complain of pruritus or tenderness in affected areas. The onset of rashes normally correlates with engraftment of donor cells.

This article seeks to provide a brief overview of cutaneous GVHD, its clinical manifestations, diagnostic methods, treatments and prognosis depending on evolution.

\section{CUTANEOUS GRAFT VERSUS-HOST \\ DISEASE}

GVHD remains a significant cause of morbidity and mortality in allogeneic hematogeneic HSCT recipients. It is defined as a syndrome in which immunocompetent donor cells recognize and attack host tissues in an immunocompromised recipient. ${ }^{5}$ The risk of GVHD increases with the use of unrelated donors, mismatched donors, older donors, mutliparous female donors, older recipients, some graft types and certain conditoning regimens. ${ }^{6}$

Acute graft versus host disease (aGvHD) generally occurs after allogeneic hematopoietic HSCT. It is a reaction of donor immune cells against host tissues. The revised National Institute for Health (NIH) criteria now define classic aGvHD as occurring within 100 days following HSCT; and late onset aGvHD, which entails typical signs and symptoms but occurs after 100 days, affecting mainly the skin, gastrointestinal tract and liver. ${ }^{7}$ Acute GVHD is stage clinically by the number and extent of organ involvement. Chronic graft-versus-host disease (cGVHD) occurs 100 days after HSCT, representing $50 \%$ of all cases and causing

Received on 03.11 .2014

Approved by the Advisory Board and accepted for publication on 27.01.2015

Work performed at the Department of Dermatology, "Dr. Jose E. Gonzalez" University Hospital of the School of Medicine of the "Universidad Autanoma de Nuevo León", - Nuevo León, Mexico.

Financial Support: None.

Conflict of Interest: None

“Dr. José E. Gonzalez" University Hospital of the "Universidad Autonoma de Nuevo León" Medical School - Nuevo León, Mexico.

"Universidad de Monterrey" - Monterrey, Mexico.

C 2016 by Anais Brasileiros de Dermatologia 
late mortality in up to $25 \%$ of patients. It is defined using the NIH criteria. ${ }^{8}$

One of the earliest and most common manifestations of GVHD is cutaneous GVHD, which consists essentially of a maculopapular rash that can begin anywhere in the body but often starts with palm and sole involvement. Early lesions are usually centered on a hair follicle, a clue for diagnosis. ${ }^{9}$ Erythematous maculopapular rashes are characteristic and tend to appear 10-30 days after transplantation. The skin is staged with percent of body surface area involved and dermatologists have traditionally used the International Bone Marrow Transplant Registry (IBMTR) grading system, which tries to diminish inter-observer variability in GVHD evaluation. ${ }^{10}$ Skin GVHD grade I involves a maculopapular rash of $<25 \%$ of body surface area (BSA); grade II entails a maculopapular rash of $25-50 \%$ BSA; grade III is typified by a maculopapular rash of $>50 \%$ BSA; while grade IV denotes a generalized erythroderma plus bullous formation. Table 1 synthetizes different grading systems for cutaneous GVHD.

\section{PATHOPHYSIOLOGY AND HISTOLOGY}

To dermatologists, knowledge of pathophysiology and the main histopathological findings of GVHD is crucial. For GVHD to occur, the donor graft must contain immunologically competent cells and the host must be incapable of mounting an effective immune response to destroy the transplanted cells. In addition, the host must express tissue antigens that are not present in the transplant donor. ${ }^{11}$

It is well-known that the interactions between chemokines and their receptors have an important role in initiating GVHD after allo-HSCT. ${ }^{12}$ Recent studies have shown that the migration of lymphocytes to secondary lymphoid tissues or target organs, such as the skin, liver and gut, is regulated by specific chemokines, which regulate the trafficking of leukocytes through interactions with a subset of seven transmembrane, G protein-coupled receptors. ${ }^{13}$ Their interactions thus play an important role in provoking organ-specific GVHD.

Histologically, the condition entails vacuolar degeneration of the basal cell layer, dyskeratotic keratinocytes and mild, mononuclear, superficial, perivascular infiltrate. Furthermore, epithelial damage occurs, initially at the tips of rete ridges and hair follicles (Figures 1 and 2)..$^{14}$ These findings suggest the following pathogenic mechanism: activated donor lymphocytes attack and destroy recipient keratinocytes. This inflammatory infiltrate is mainly composed of CD4 and CD8 lymphocytes. ${ }^{15}$

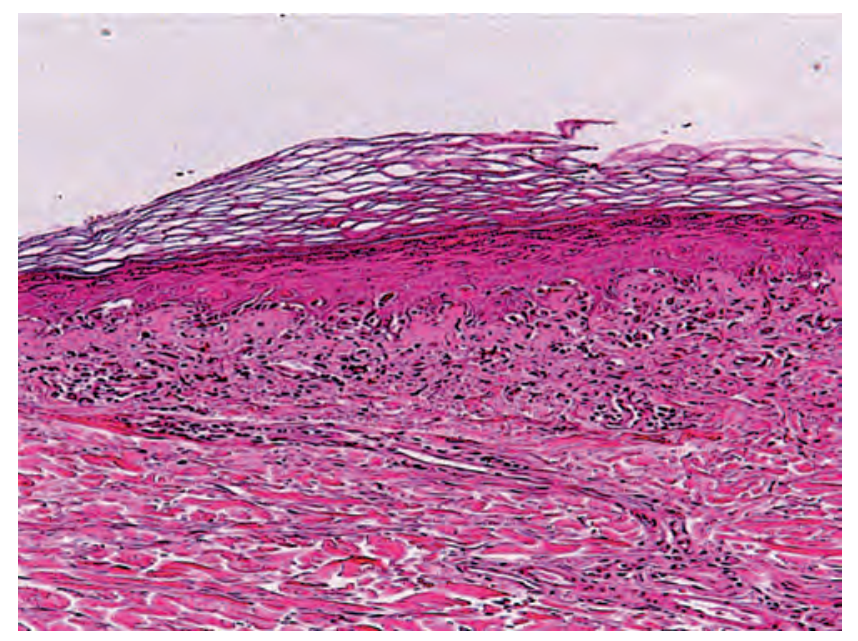

Figure 1: Histological aspects of cutaneous GVHD. Skin biopsy of cutaneous GVHD: hyperkeratosis, hypergranulosis associated with lichenoid inflammatory infiltrate is observed. (10X, HyE)

TABLE 1: Histopathology described by Lerner et al. for diagnosing GvHD. 1994 Consensus Conference on Acute GVHD Grading, focusing on Skin GVHD and International Bone Marrow Transplant Registry (IBMTR) staging of GVHD

\begin{tabular}{|c|c|c|c|c|c|}
\hline \multicolumn{2}{|c|}{$\begin{array}{l}\text { Histopathology described by Lerner et al. for } \\
\text { diagnosing GVHD ( } 27)\end{array}$} & \multicolumn{2}{|c|}{$\begin{array}{l}1994 \text { Consensus Conference on Acute } \\
\text { GVHD Grading. (54) }\end{array}$} & \multicolumn{2}{|c|}{$\begin{array}{l}\text { International Bone Marrow Transplant } \\
\text { Registry (IBMTR) }\end{array}$} \\
\hline Grade & Skin & Stage & Skin & Grade & GVHD \\
\hline 0 & Normal skin & 0 & No GVHD rash & I & Skin stage $1-2$ \\
\hline 1 & Mild vacuolization of epidermal cells & 1 & Maculopapular rash<25\% BSA & II & Skin stage 3 or liver/gut stage I \\
\hline 2 & $\begin{array}{l}\text { Diffuse vacuolization of basal cells } \\
\text { with scattered dyskeratotic bodies }\end{array}$ & 2 & Maculopapular rash 25 - 50\% BSA & & \\
\hline 3 & Sub-epidermal cleft formation & 3 & Maculopapular rash > 50\% BSA & III & $\begin{array}{l}\text { Skin Stage } 3 \text { or liver stage } 2-3 \text { / } \\
\text { gut stage } 2-4\end{array}$ \\
\hline 4 & Complete epidermal separation & 4 & $\begin{array}{l}\text { Generalized erythroderma plus } \\
\text { bullous formation }\end{array}$ & IV & Skin stage 4 or liver stage 4 \\
\hline
\end{tabular}

*BSA: Body surface area; GVHD: Graft-versus-host disease. 


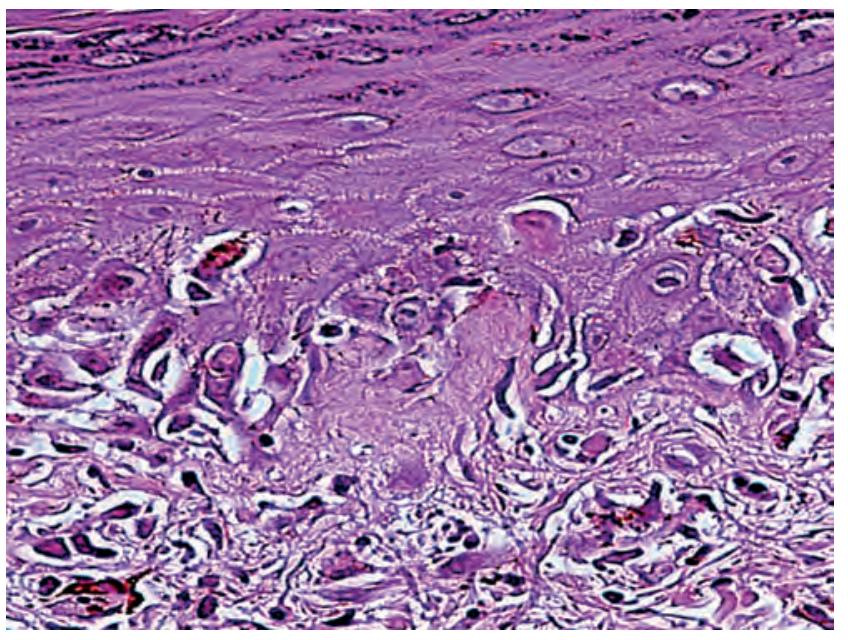

FIGURE 2: Histological aspects of cutaneous GVHD. Skin biopsy of cutaneous GVHD: Epidermal Basal cell apoptosis associated with melanin pigment deposits are present near the basement membrane zone. (40X, HyE)

Risk factors for acute cutaneous GVHD have been described, including: a diagnosis of chronic myeloid leukaemia, HLA disparity, receipt of more than one HSCT, conditioning regimens including total body irradiation, and GVHD prophylaxis regimens other than ciclosporin plus methotrexate. ${ }^{16}$ This group of patients (patients with all the risk factors described above) should me monitorated closely to detect early sings of cutaneaos GVHD.

\section{CLINICAL MANIFESTATIONS}

Acute cutaneous graft-versus host disease usually presents with a pruritic and painful rash, approximately 2-3 weeks after HSCT. Clinically, on physical examination, a morbilliform exanthem usually manifests, with red to violaceous lesions, initially appearing on the palms, soles, cheeks, neck, ears, and upper trunk (Figures 3 and 4). The rash may spread around the entire body and, if severe, vesicles, bullae, and erythroderma can develop. Generalized desquamation also emerges. ${ }^{17}$

Chronic GvHD (c-GVHD) is the most common complication after transplantation, reported in $60-80 \%$ of patients. The skin is affected in over $90 \%$ of cases, often resulting in long-term complications such as cosmetic, functional, and even life-threatening disorders and sequelae. ${ }^{14}$ Since this chronic entity involves a wide spectrum of manifestations, we will expand further on its clinical aspects. The cutaneous involvement of this entity has traditionally been divided into two forms: limited and extensive. ${ }^{14} \mathrm{How}-$ ever, dermatologists have long recognized two stages in cGvHD: lichenoid cGvHD, appearing early on; and sclerodermatous cGvHD, manifesting later. ${ }^{18}$ The histological picture of lichenoid GVHD is similar to that of classic lichen planus: hyperkeratosis, hypergranulosis, acanthosis and dyskeratotic keratinocytes with basal cell vacuolization. ${ }^{19} \mathrm{~A}$ moderate to marked, bandlike infiltrate along the dermal epidermal junction, occasionally extending to the deep dermis, is essential for diagnosis, as vacuolar degeneration of the basal cell layer is a common, long-lasting finding in patients after allo-HSCT. ${ }^{20}$

Sclerodermatous GVHD can affect every skin level. In lichen sclerosus, epidermal atrophy, edema and homogenization of the collagen in the upper dermis are usual findings. ${ }^{20}$ In morphoea lesions, there are three collagen sclerosis patterns: pandermal, patched

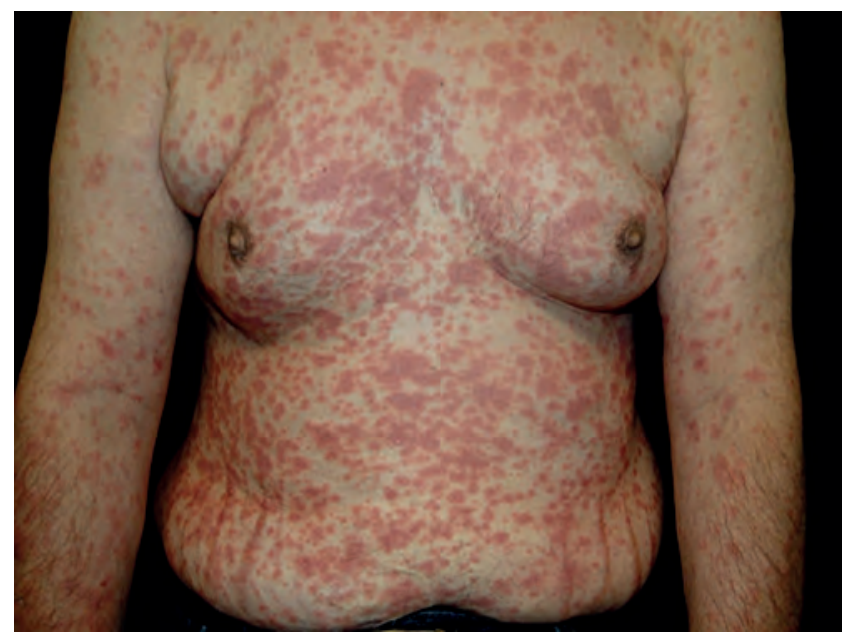

FIGURE 3: Clinical manifestations of cutaneous GVHD. Patient with GVHD grade 3, maculopapular erythematous rash affecting the anterior portion of thorax and extremities

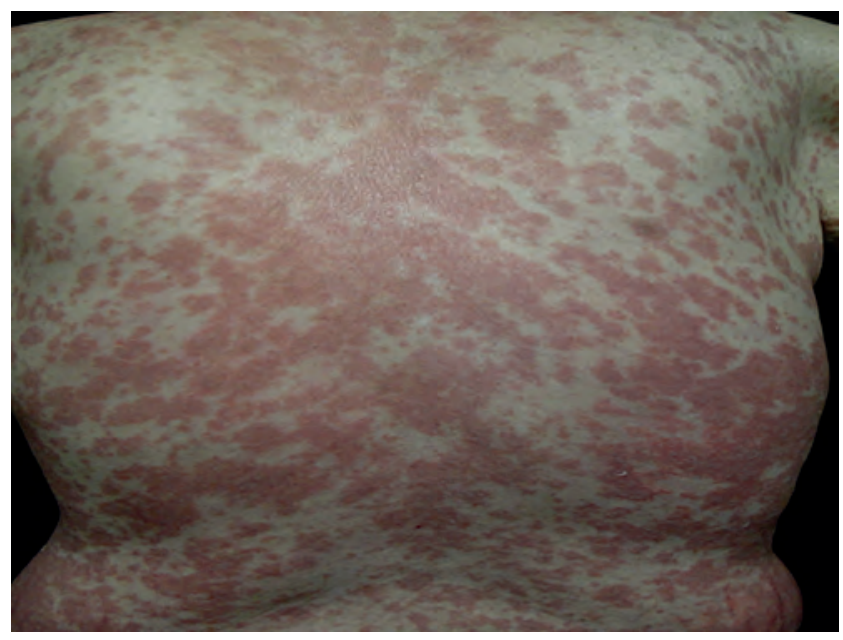

Figure 4: Clinical manifestations of cutaneous GVHD. Patient with GVHD grade 3, maculopapular erythematous rash affecting the posterior portion of thorax 
and deep dermal. Histological changes involving panniculitis with fibrosis and fasciitis are also frequent. ${ }^{21}$

Importantly, sclerodermatous GvHD is preceded by lichenoid lesions only in $40 \%$ of cases, and not all patients with lichenoid GvHD progress to the sclerodermatous phase, which is associated with bad prognosis and is the last stage of cutaneous GvHD, usually occurring subsequently to day 500 after AHSCT. ${ }^{22}$

Clinically, lichenoid graft-versus-host disease patients present with violaceous or erythematous papules and plaques, including a fine scale on top that can coalesce. It frequently starts on the trunk and becomes generalized a few weeks later, although in some cases lesions remain localized. Furthermore, it is preceded by scattered hyperpigmented macules (leopard skin) and keratosis pilaris. ${ }^{20}$ The sclerosis presents in the form of lichen sclerosus, morphoea and/or ripply skin, correlating with the histological level of sclerotic involvement. ${ }^{23}$ Bullous lesions, ulcers, poikilodermatous changes, pyogenic granuloma-like lesions, subcutaneous tissue eventrations, anetoderma and pigmentary changes, can all be found. ${ }^{20}$ Special follow-up should be given to these patients with cutaneous involvement, given the risk of joint retraction and diminished mobility.

Special consideration should be extended to patients treated with a reduced intensity condition regimen (RIC). This conditioning regimen is being used in developing countries, with positive responses. Unlike myeloablative regimens, RIC schemes are associated with a decreased release of pro-inflammatory cytokines, due to limited tissue damage during their administration, as well as a transient and potentially tolerogenic state of mixed donor/host chimerism. ${ }^{24}$ These differences might account for the lower rates of severe GvHD after unrelated HSCT with a non-myeloablative RIC, as compared to myeloablative conditioning. ${ }^{25}$

Patients receiving reduced intensity regimens, which do not result in marrow ablation, often have a later onset of GVHD. This is due both to the later engraftment and the damage from the preparative regimen, producing cytokines that drive the immune responses, thus resulting in clinical GVHD. As the rash progresses, it may become confluent. In severe cases, blisters may occur. Consequently, dermatologists have greater contact with these patients at their clinics.

\section{DIAGNOSIS}

Cutaneous GVHD is usually suspected based on the clinical presentation. A biopsy can be used to confirm the diagnosis and should be used when there are competing diagnoses, such as infection and drug reaction, in the differential. These skin biopsies can reveal dyskeratotic keratinocytes, lymphocyte exocy- tosis, basal cell necrosis, depletion of Langerhans cells, and satellite lymphocytes next to the dyskeratotic keratinocytes. Importantly, not all the findings necessarily feature in every skin biopsy and histology is not always pathognomonic. ${ }^{26}$

The aformentioned grading system for diagnosing GvHD is based on the histopathology by Lerner et al.: Grade $0 \pm$ normal skin, Grade I \pm mild vacuolization of epidermal cells, Grade II \pm diffuse vacuolization of basal cells with scattered dyskeratotic bodies, Grade III \pm sub-epidermal cleft formation and Grade IV \pm complete epidermal separation. ${ }^{27}$ A skin biopsy may be considered if eruptions suggesting GVHD develop during early stages after HSCT. Significantly, biopsies in GVHD are not pathognomic and usually not necessary to diagnose cutaneous GVHD.

\section{TREATMENT}

Cutaneous involvement is the most frequent manifestation of GVHD and dermatologists should be aware of the clinical signs of aGVHD to treat it as early as possible.

Glucocorticoids remain the first-line therapy for patients who develop acute GVHD, often in combination with other agents such as antithymocyte globulin, CsA, tacrolimus, MMF or monoclonal antibodies. ${ }^{28}$ However, only $20-40 \%$ of patients show a durable response. ${ }^{29} \mathrm{~A}$ major side effect of systemic glucocorticoids is an increased risk of infection and relapse of the underlying malignancy. ${ }^{30}$ Second-line treatments or salvage therapy should be started if: the disease progresses after 3 days, there is no change after 7 days or the response is incomplete after 14 days of corticosteroid therapy. ${ }^{31}$

Topical immunosuppressive therapies for cGVHD are linked to less toxicity compared with systemic treatment. Their use can improve response rates and thus, facilitate dose reduction, reduce toxicity or even help circumvent the application of systemic drugs in cases of mild cGVHD. Topical calcineurin inhibitors are of special interest on anatomical sites such as the face or intertriginous areas, where potent, topical steroids should be used with caution. ${ }^{32}$ The advantage topical pimecrolimus has over tacrolimus is its improved local tolerability. It is preferred in the treatment of mild cGVHD, facial manifestations and for children.

Alternative therapies are available for these patients. Although hematopoietic cell transplanted patients are counseled to avoid ultraviolet radiation due to possible GVHD flare or increased risk of skin cancer, psoralens plus ultraviolet A light (PUVA) or narrow band-ultraviolet $B$ phototherapy are the treatment choices for sclerotic cGVHD lesions. The action mechanisms of phototherapy include antiproliferative effects 
as well as immunomodulation, influencing cytokine production, cell activation, antigen presentation and apoptosis of various cells including T lymphocytes. ${ }^{33}$ The longer the radiation wavelength, the deeper the skin absorption: UVB is primarily absorbed in the epidermis, whereas UVA penetrates more deeply into the dermis. Some of the phototherapies currently used to treat cutaneous GvHD will be outlined.

\section{EXTRACORPOREAL PHOTOPHERESIS}

Significant improvement has been reported in patients with chronic cutaneous GVHD (cGVHD) after treatment with extracorporeal photopheresis $(\mathrm{ECP}){ }^{34}$ The procedure involves peripheral blood (PB) leucocytes being isolated from the patient and irradiated with UVA light in combination with a photo-sensitizing agent such as psoralens. This can be taken orally by the patient 2 hours before the procedure or added directly to the buffy coat bag containing the leucocyte-rich fraction. ${ }^{35}$ ECP is known to affect cytokine release and changes in Th1/ Th2 ratios might explain some of its therapeutic benefits. ${ }^{36}$ In exclusively cutaneous lichenoid cGVHD, extracorporeal photophoresis has proven to be the most effective therapy. ${ }^{18}$ Regarding patients with sclerodermatous graft-versus-host disease, etretinate and extracorporeal photophoresis are the most effective treatments. ${ }^{18}$ Recently, imatinib was found to be useful in several cases. ${ }^{37}$

Some major complications of extracorporeal photopheresis can occur, usually involving the longterm indwelling central venous apheresis catheters, which are needed to maintain the long-term vascular access required for treatment, transient hypotension during the procedure, post-reinfusion fever and erythema and nausea related to oral psoralen ingestion. ${ }^{38}$

\section{UVA-1 PHOTOTHERAPY}

UVA-1 phototherapy induces apoptosis of skin-infiltrating $\mathrm{T}$ cells, thus causing a gradual reduction of the inflammatory infiltrate. ${ }^{39}$ In addition, radiation is a potent inducer of the immunosuppressive cytokine interleukin 10 in human keratinocytes. Furthermore, a dose-dependent upregulation of collagenase activity has been reported, which could be responsible for the clinical improvement seen in patients with scleroderma. ${ }^{40}$ UVA-1 is usually well-tolerated, with very few side effects. Erythema, tanning, polymorphic light eruptions, ilching and recrudescence of the herpes simplex infection are the main acute adverse effects. UVA-1 also has significant advantages over PUVA, as it avoids nausea, vomiting, long-lasting skin photosensitivity and the need for eye protection. Moreover, PUVA therapy often fails and is not well-tolerated by patients since it can cause local pain and blistering. ${ }^{41}$
As primary therapy for acute GVHD of the skin, UVA-1 treatment is feasible, well-tolerated and effective in an outpatient setting, irrespective of age or conditioning regimen type. Systemic steroids can thus be avoided and/or tapered more rapidly in some patients. Nevertheless, patients must be monitored carefully for early detection of possible secondary cutaneous malignancies. ${ }^{42}$

UVA-1 irradiation seems to be a suitable and effective primary treatment option in all patients with acute GVHD of the skin, regardless of the conditioning regimen type. The impact of RICs on the incidence and severity of acute GVHD, and on its response to treatment, has not been evaluated in depth. Patients with RICs demonstrated a later median onset of acute GVHD compared with non-RIC patients. Further, patients with RICs required more treatment sessions and a higher median dose of UVA-1 irradiation to treat acute GVHD of the skin than patients with non-RIC HCT. This may be due to their lower production of tumor necrosis factor-a, increased T-regulatory cell numbers and delayed emergence of activated donor DC, unlike non-RIC patients. ${ }^{42,43}$

A major concern surrounding UVA treatments and the secondary effects is the potentially long-term, carcinogenic influence of UVA-1 (315-400 nm) therapy, though UVB radiation (wavelength band $280-315 \mathrm{~nm}$ ) is regarded as the most carcinogenic modality. ${ }^{44} \mathrm{How}-$ ever, malignant melanoma development is considered unrelated to UVA irradiation, while melanoma risk is not associated with cumulative, but rather with more intensive and intermittent, exposure to sunlight. ${ }^{45}$

\section{SKIN TRASNPLANTATION}

In cases of skin ulceration due to refractory chronic cutaneous GVHD after allo-HSCT, there are few reports in the literature about treatment with skin transplantation. J Ammer et al. reported a case of refractory treatment in patients with chronic GVHD after allo-HSCT. The report described successful treatment of a patient via split-thickness skin transplantation from the HLA-identical donor. ${ }^{46}$ In 1985, Knobler et al. published one of the earliest reports on treatment for ulcerating chronic GVHD using skin grafts from the BM donor. ${ }^{47}$ Another three studies reported successful allogeneic skin grafting in severe chronic GVHD from the HLA-identical stem cell donor. ${ }^{48}$ Recently, a French cohort treated a patient for extensive ulcerating cutaneous GVHD, with a two-step skin transplantation of the HLA-identical sister, resulting in complete coverage of the skin lesion and subsequent withdrawal of immunosuppression..$^{49}$ Table 2 summarizes the different treatments available for skin GVHD. 
TABLE 2: Current treatments available for skin GVHD. Description of treatment uses and adverse effects is provided

\begin{tabular}{|c|c|}
\hline Treatment & General characteristics \\
\hline Steroids & $\begin{array}{l}\text { - Immunosuppressive medications, used to prevent acute GVHD alone or in combination with other agents such as } \\
\text { ATG, CSA, tacrolimus, MMF or monoclonal antibodies. } \\
\text { - Only } 20-40 \% \text { of patients show a durable response. } \\
\text { - Side effects: Increased risk of infection and of relapse of the underlying malignancy, skin atrophy. } \\
\text { - Sort by potency: } \\
\text { I. Mild (lower-potency steroid): Hydrocortisone } 0.1-14 \\
\text { II. Moderate (mid-potency steroid): Triamcinolone acetonide } 0.05-0.1 \% \\
\text { III. Potent (high-potency steroid): Mometasone furoate } 0.1 \% \\
\text { IV. Very potent (ultra-high-potency steroid): Clobetasol propionate } 0.05 \%\end{array}$ \\
\hline $\begin{array}{l}\text { Extracorporeal } \\
\text { photopheresis }\end{array}$ & $\begin{array}{l}\text { - Glucocorticoid-refractory acute and chronic GVHD } \\
\text { - Peripheral blood leucocytes are isolated from the patient and irradiated with UVA light in combination with a pho- } \\
\text { to-sensitizing agent such as psoralens. } \\
\text { - Cytokine release and changes in Th1/Th2 ratios might explain some of its therapeutic benefits. } \\
\text { - Side effects: hypotension during the procedure, post-reinfusion fever and erythema and nausea related to oral pso- } \\
\text { ralen ingestion. }\end{array}$ \\
\hline $\begin{array}{l}\text { UVA-1 } \\
\text { phototherapy }\end{array}$ & $\begin{array}{l}\text { - Induces apoptosis of skin-infiltrating T cells, thereby causing a gradual reduction of the inflammatory infiltrate. } \\
\text { - Dose-dependent up-regulation of collagenase activity. } \\
\text { - Highly effective in treating acute cutaneous GVHD with an overall response rate of } 94.3 \% \text {. } \\
\text { - Feasible, well-tolerated and effective in treating chronic as well as acute GVHD. } \\
\text { - This form of phototherapy is currently not widely available. } \\
\text { - Few side effects: Erythema, tanning, polymorphic light eruptions, recrudescence of herpes simplex infection. } \\
\text { - Potential long-term adverse effect: carcinogenic. }\end{array}$ \\
\hline $\begin{array}{l}\text { Skin } \\
\text { transplantation }\end{array}$ & $\begin{array}{l}\text { - Alternative in cases of skin ulceration due to refractory chronic cutaneous GVHD. } \\
\text { - Split-thickness transplantation from the HLA-identical donor. }\end{array}$ \\
\hline
\end{tabular}

\section{FOLLOW-UP RECOMENDATIONS}

Besides the different aforementioned treatments, there are recommendations to be considered for these patients during follow-up. Regular lubrication is mandatory to maintain skin integrity. Moisturizers, urea $(3-10 \%)$ and glycerol in particular are hydrating and help to regenerate the injured transepidermal lipid barrier. Dermatological examination of skin and mucous membranes every 12 months is highly recommended. In patients with a history of cutaneous malignancies, the screening interval should be shortened to at least 6 months, with an offer of special evaluation for potential cutaneous infection. After withdrawal of immunosuppression, cutaneous examinations should be continued every year. ${ }^{31}$ Dermatoscopic screening should also be included, as melanoma risk is significantly elevated in patients following HSCT. ${ }^{50}$

\section{CONCLUSION}

We conclude that due to the increasing incidence of hematological diseases, more accessible conditioning regimens like RICs in developing countries, and the new HSCT modalities, hematopoietic stem cell transplantation is now a common therapy worldwide. As explained, GVHD is highly prevalent in patients receiving a HSCT; skin GvHD is the most common manifestation following HSCT. It can appear as an acute or chronic comorbidity, and it affects greatly patients' quality of life. Thus, it is essential for dermatologists to know the different aspects of skin GVHD, as well as its proper diagnosis, prevention and treatment. 


\section{REFERENCES}

1. Kernan NA, Collins NH, Juliano L, Cartagena T, Dupont B, O'Reilly RJ. Clonable $\mathrm{T}$ lymphocytes in $\mathrm{T}$ cell-depleted bone marrow transplants correlate with development of graft-v-host disease. Blood. 1986;68:770-3.

2. Jagasia M, Arora M, Flowers ME, Chao NJ, McCarthy PL, Cutler CS, et al. Risk factors for acute GVHD and survival after hematopoietic cell transplantation. Blood. 2012;119:296-307.

3. Weisdorf D, Haake R, Blazar B, Miller W, McGlave P, Ramsay N, et al. Treatment of moderate/severe acute graft-versus-host disease after allogeneic bone marrow transplantation: an analysis of clinical risk features and outcome. Blood. 1990;75:1024-30.

4. Farmer ER. Human cutaneous graft-versus-host disease. J Invest Dermatol 1985;85:124s-128s.

5. Garnett C, Apperley JF, Pavlů J. Treatment and management of graft-versus-host disease: improving response and survival. Ther Adv Hematol. 2013;4:366-78.

6. Jacobsohn DA, Vogelsang GB. Acute graft versus host disease. Orphanet J Rare Dis. 2007:2:35

7. Dignan FL, Clark A, Amrolia P, Cornish J, Jackson G, Mahendra P, et al. Diagnosis and management of acute graft-versus-host disease. Br J Haematol. 2012;158:30-45

8. Dignan FL, Amrolia P, Clark A, Cornish J, Jackson G, Mahendra P, et al. Diagnosis and management of chronic graft-versus-host disease. Br J Haematol. 2012;158:46-61.

9. Friedman KJ, LeBoit PE, Farmer ER. Acute follicular graft-vs-host reaction. A distinct clinicopathologic presentation. Arch Dermatol. 1988;124:688-91.

10. Przepiorka D, Weisdorf D, Martin P, Klingemann HG, Beatty P, Hows J, et al. 1994 Consensus Conference on Acute GVHD Grading. Bone Marrow Transplant. 1995; $15: 825-8$

11. Botari CM, Nunes AJ, Souza MP, Orti-Raduan ES, Salvio AG. Oral chronic graftversus-host disease: analysis of dendritic cells subpopulations. An Bras Dermatol. 2014;89:632-7.

12. Inamoto $Y$, Murata M, Katsumi A, Kuwatsuka $Y$, Tsujimura A, Ishikawa $Y$, et al. Donor single nucleotide polymorphism in the CCR9 gene affects the incidence of skin GVHD. Bone Marrow Transplant. 2010;45:363-9.

13. Campbell DJ, Kim CH, Butcher EC. Chemokines in the systemic organization of immunity. Immunol Rev. 2003;195:58-71.

14. Johnson ML, Farmer ER. Graft-versus-host reactions in dermatology. J Am Acad Dermatol. 1998;38:369-92.

15. Aractingi $\mathrm{S}$, Chosidow 0 . Cutaneous graft-versus-host disease. Arch Dermatol. 1998;134:602-12.

16. Vargas-Díez E, Fernández-Herrera J, Marin A, Cámara R, García-Díez A. Analysis of risk factors for acute cutaneous graft-versus-host disease after allogeneic stem cell transplantation. Br J Dermatol. 2003;148:1129-34.

17. Nijhawan A, Drolet BA. Graft-versus-host disease. Adv Dermatol. 2001;17:11539.

18. Peñas PF, Fernández-Herrera J, García-Diez A. Dermatologic treatment of cutaneous graft versus host disease. Am J Clin Dermatol. 2004;5:403-16.

19. Vargas-Díez E, García-Díez A, Marín A, Fernández-Herrera J. Life-threatening graft-vs-host disease. Clin Dermatol. 2005;23:285-300.

20. Peñas PF, Jones-Caballero M, Aragüés M, Fernández-Herrera J, Fraga J, GarcíaDíez A. Sclerodermatous graft-vs-host disease: clinical and pathological study of 17 patients. Arch Dermatol. 2002;138:924-34.

21. Janin A, Socie G, Devergie A, Aractingi S, Esperou H, Verola O, et al. Fasciitis in chronic graft-versus-host disease. A clinicopathologic study of 14 cases. Annals of internal medicine. 1994;120(12):993-8.

22. Skert C, Patriarca F, Sperotto A, Cerno M, Fili C, Zaja F,et al. Sclerodermatous chronic graft-versus-host disease after allogeneic hematopoietic stem cell transplantation: incidence, predictors and outcome. Haematologica. 2006;91:25861.

23. Peñas PF, Jones-Caballero M, Aragüés M, Fernández-Herrera J, García-Díez A. The clinical and histologic spectrum of chronic graft-versus-host disease. J Am Acad Dermatol. 2006;55:729.

24. Manilay JO, Pearson DA, Sergio JJ, Swenson KG, Sykes M. Intrathymic deletion of alloreactive $T$ cells in mixed bone marrow chimeras prepared with a nonmyeloablative conditioning regimen. Transplantation. 1998;66:96-102.

25. Couriel DR, Saliba RM, Giralt S, Khouri I, Andersson B, de Lima M, et al. Acute and chronic graft-versus-host disease after ablative and nonmyeloablative conditioning for allogeneic hematopoietic transplantation. Biol Blood Marrow Transplant. 2004;10:178-85.
26. Esteban JM, Somlo G. Skin biopsy in allogeneic and autologous bone marrow transplant patients: a histologic and immunohistochemical study and review of the literature. Mod Pathol. 1995;8:59-64.

27. Lerner KG, Kao GF, Storb R, Buckner CD, Clift RA, Thomas ED. Histopathology of graft-vs.-host reaction (GvHR) in human recipients of marrow from HL-A-matched sibling donors. Transplant Proc. 1974;6:367-71.

28. Chao NJ, Chen BJ. Prophylaxis and treatment of acute graft-versus-host disease. Semin Hematol. 2006;43:32-41.

29. Vogelsang GB, Lee L, Bensen-Kennedy DM. Pathogenesis and treatment of graftversus-host disease after bone marrow transplant. Annu Rev Med. 2003;54:2952.

30. Krejci M, Doubek M, Buchler T, Brychtova Y, Vorlicek J, Mayer J. Mycophenolate mofetil for the treatment of acute and chronic steroid-refractory graft-versus-host disease. Ann Hematol. 2005;84:681-5

31. Peñas PF, Zaman S. Many faces of graft-versus-host disease. Australas $\mathrm{J}$ Dermatol. 2010;51:1-10

32. Marks C, Stadler M, Häusermann P, Wolff D, Buchholz S, Stary G, et al. GermanAustrian-Swiss Consensus Conference on clinical practice in chronic graft-versushost disease (GVHD): guidance for supportive therapy of chronic cutaneous and musculoskeletal GVHD. Br J Dermatol. 2011;165:18-29.

33. Greinix HT, Socié G, Bacigalupo A, Holler E, Edinger MG, Apperley JF, et al. Assessing the potential role of photopheresis in hematopoietic stem cell transplant. Bone Marrow Transplant. 2006;38:265-73.

34. Seaton ED, Szydlo RM, Kanfer E, Apperley JF, Russell-Jones R. Influence of extracorporeal photopheresis on clinical and laboratory parameters in chronic graft-versus-host disease and analysis of predictors of response. Blood. 2003;102:1217-23.

35. Darvay A, Salooja N, Russell-Jones R. The effect of extracorporeal photopheresis on intracellular cytokine expression in chronic cutaneous graft-versus-host disease. J Eur Acad Dermatol Venereol. 2004;18:279-84.

36. Di Renzo M, Rubegni P, De Aloe G, Paulesu L, Pasqui AL, Andreassi L, et al. Extracorporeal photochemotherapy restores Th1/Th2 imbalance in patients with early stage cutaneous T-cell lymphoma. Immunology. 1997;92:99-103.

37. Moreno-Romero JA, Fernández-Avilés F, Carreras E, Rovira M, Martínez C Mascaró JM Jr. Imatinib as a potential treatment for sclerodermatous chronic graft-vs-host disease. Arch Dermatol. 2008;144:1106-9.

38. Apisarnthanarax N, Donato M, Körbling M, Couriel D, Gajewski J, Giralt S, et al. Extracorporeal photopheresis therapy in the management of steroid-refractory or steroid-dependent cutaneous chronic graft-versus-host disease after allogeneic stem cell transplantation: feasibility and results. Bone Marrow Transplant. 2003:31:459-65.

39. Morita A, Werfel T, Stege H, Ahrens C, Karmann K, Grewe M, et al. Evidence that singlet oxygen-induced human $T$ helper cell apoptosis is the basic mechanism of ultraviolet-A radiation phototherapy. J Exp Med. 1997;186:1763-8.

40. Petersen MJ, Hansen C, Craig S. Ultraviolet A irradiation stimulates collagenase production in cultured human fibroblasts. J Invest Dermatol. 1992;99:440-4.

41. Wetzig T, Sticherling M, Simon JC, Hegenbart U, Niederwieser D, Al-Ali HK Medium dose long-wavelength ultraviolet A (UVA1) phototherapy for the treatment of acute and chronic graft-versus-host disease of the skin. Bone Marrow Transplant. 2005;35:515-9.

42. Schlaak M1, Schwind S, Wetzig T, Maschke J, Treudler R, Basara N, et al. UVA (UVA-1) therapy for the treatment of acute GVHD of the skin. Bone Marrow Transplant. 2010;45(:1741-8.

43. Turner BE, Kambouris ME, Sinfield L, Lange J, Burns AM, Lourie R, et al. Reduced intensity conditioning for allogeneic hematopoietic stem-cell transplant determines the kinetics of acute graft-versus-host disease. Transplantation. 2008;86:968-76.

44. de Gruijl FR. Photocarcinogenesis: UVA vs. UVB radiation. Skin Pharmacol Appl Skin Physiol. 2002;15:316-20.

45. Jhappan C, Noonan FP, Merlino G. Ultraviolet radiation and cutaneous malignant melanoma. Oncogene. 2003;22:3099-112.

46. Ammer J, Prantl L, Holler B, Landfried K, Wolff D, Karrer S, et al. Successful treatment of a refractory skin ulcer in chronic cutaneous GvHD after allogeneic HSCT with split-thickness skin allografting from the stem cell donor. Bone Marrow Transplant. 2012;47:1368-9

47. Knobler HY, Sagher U, Peled IJ, Wexler MR, Steiner D, Rubinstein N, et al. Tolerance to donor-type skin in the recipient of a bone marrow allograft. Treatment of skin ulcers in chronic graft-versus-host disease with skin grafts from the bone marrow donor. Transplantation. 1985;40:223-5. 
48. Kondo S, Tamura K, Makino S, Takamatsu Y. Allogeneic skin grafting for extensive skin chronic graft-versus-host disease. Int J Hematol. 1994;60:151-5.

49. Crocchiolo R, Nicolini FE, Sobh M, Ducastelle-Lepretre S, Labussiere H, Dubois $V$, et al. Treatment of a severe extensive cutaneous chronic GVHD after allo-HSCT using glycerolyzed skin allografts and cultured epidermis from the same donor. Bone Marrow Transplant. 2011;46:1153-5.

50. Curtis RE, Rowlings PA, Deeg HJ, Shriner DA, Socíe G, Travis LB, et al. Solid cancers after bone marrow transplantation. N Engl J Med. 1997;336:897-904.
MAILING ADDRESS:

Cesar Daniel Villarreal Villarreal

Hematology, "Dr. Rodrigo Barragán Villarreal" Building, 2nd floor.

Ave. Madero y Ave. Gonzalitos s/ $n$,

Colonia Mitras Centro,

C.P. 64460 Monterrey, N.L. Mexico

E-mail: cesardvv@gmail.com

How to cite this article: Villarreal-Villarreal CD, Salas-Alanis JC, Jaime-Perez JC, Ocampo-Candiani J. Cutaneous graft-versus host disease after hematopoietic stem cell transplant - a review. An Bras Dermatol. 2016;91(3):336-43. 